\title{
Software tool used for automated design of customizable product
}

\author{
Roxana Pescaru ${ }^{1}$, Panagiotis Kyratsis ${ }^{2}$, and Gheorghe Oancea ${ }^{1, *}$ \\ ${ }^{1}$ Transilvania University of Brasov, Manufacturing Engineering Department, Mihai Viteazu No. 5, \\ Brasov, Romania \\ ${ }^{2}$ Western Macedonia University of Applied Sciences, Department of Mechanical Engineering and \\ Industrial Design, Kila Kozanis, Greece
}

\begin{abstract}
The paper presents an original software tool implemented for an automated design methodology associated to a customizable product from footwear industry. The software tool is written in Visual Basic for Application and is integrated in CATIA environment. It is an easy to use software tool and combines reverse engineering with parametric design of a product that has complex shapes with many curves. The final result is a solid CAD model obtained in an automatically mode.
\end{abstract}

\section{Introduction}

Nowadays the Reverse Engineering (RE) became a common technology used in different fields such as [1, 2]: automotive, aerospace, medical engineering, entertainment, clothing and footwear, architecture and arts. RE is defined as a reinvention technology which uses the processes of measuring, analysing, and testing to reconstruct an object [1].

In the RE process are used different commercial software systems for point cloud handling and object redesigning [1,3-8]. Usually a specific methodology used by the designer in commercial software systems for the redesigning process and the product is obtained in a parameterised mode [3-5]. The specific methodology can be also implemented in specific software tools for obtaining the CAD model corresponding to a customizable product, in an automatically mode. The paper aims to present such a software tool based on the methodology developed by the authors for a customizable product from the area footwear [4].

\section{Software tool presentation}

The software tool has been developed using Visual Basic for Application (VBA) under CATIA commercial software system. The VBA language has been used in the process of software tool developing that can be launched from the CATIA environment. The interface shown in Fig. 1 (in editing mode), has been designed in the Visual Basic environment [9, $10]$ and the application which manages the components placed on it has been conceived to

\footnotetext{
*Corresponding author: gh.oancea@unitbv.ro
} 
ensure the flow of information in the CATIA design environment.

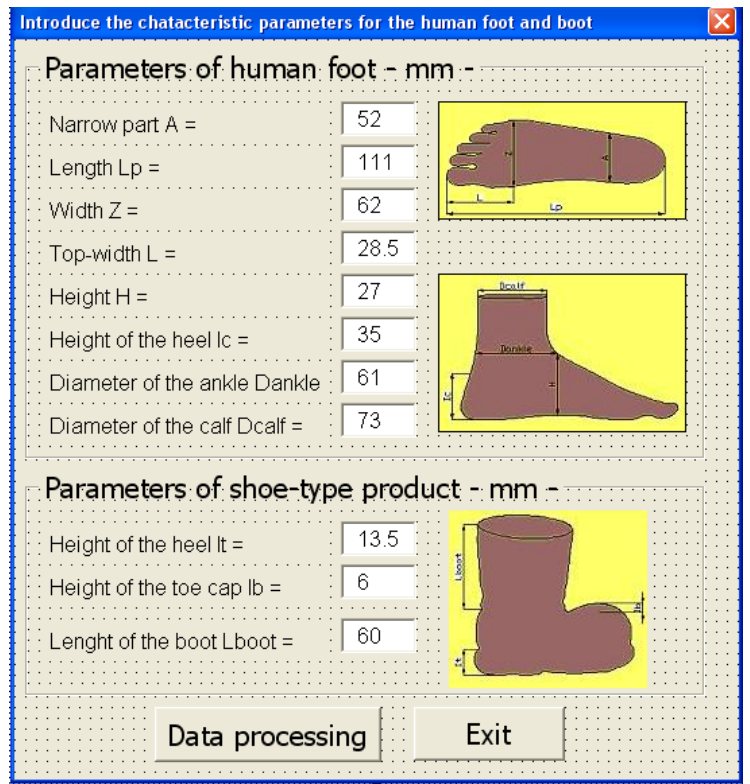

Fig. 1. Designed graphical user interface.

\section{CISTOMIZATION OF FOOTWEAR TYPE PRODUCTS}

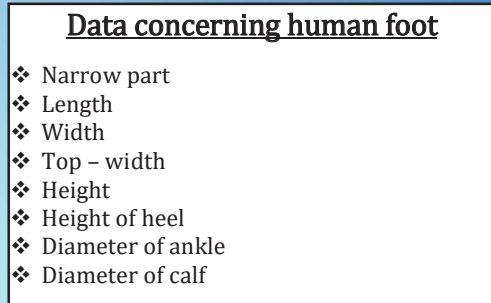

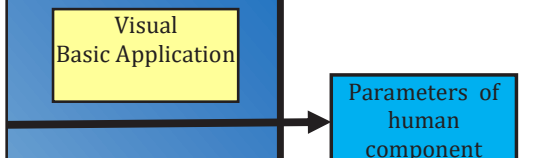

Data concerning the shoe

* Height of heel

* Height of toe cap

* Length of boot

\begin{tabular}{|l|}
\hline File management \\
* Open file "Design_table11" \\
* Write file "Design_table11" \\
* Save file "Design_table1" \\
\hline
\end{tabular}

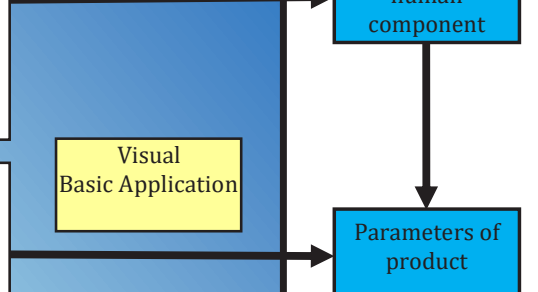

Change product

* Update sole of boot

* Update toe cap of boot

* Update lower part of boot

* Update upper part of boot

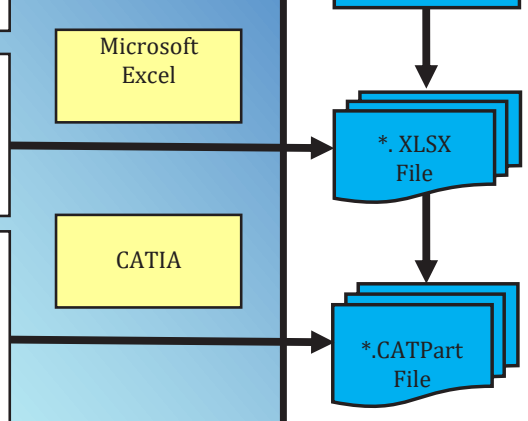

Fig. 2. Flow chart for customization of products of footwear type implemented in software tool. 
On the interface are presented, in a graphical form, the product type and the corresponding human foot with the associated parameters.

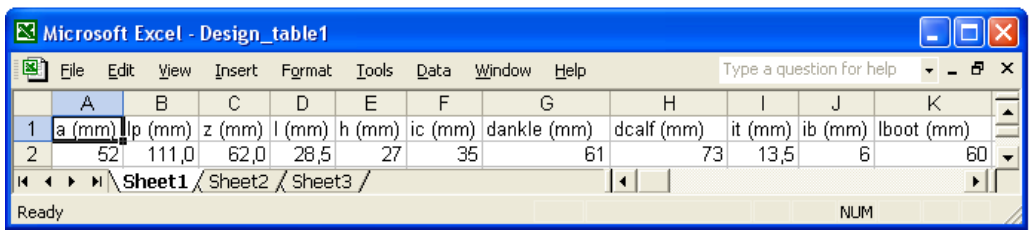

Fig. 3. Design table in Excel file.

According to the flow chart shown in Fig. 2, two interrelated modules are required in order to obtain the final product. The first module that consists of the VBA application has a role in the introduction of the data relating to the human component and is delivered as numeric values that represent the parameters required for the footwear customization. The second module is necessary in order to modify the product, using the CATIA environment in accordance with the values entered by means of the first module. The CAD model of the footwear product is modelled in a parametric mode using the RE methodology developed by the authors [4]. These two modules are interconnected in such a way that the user perceives the system as a whole without noticing when passing from one module to another.

In order to facilitate the introduction of the parameters necessary to carrying out the automated attainment of the curve/surfaces in the CATIA environment, the authors have chosen the design table method. The aim of the design table [11] is to control the parameters of a CAD model by means of external values. For any design table, the user has to associate the parameters of the model obtained in CATIA with the data stored in the table. By creating the associations, the user specifies which of the model parameters are set in correspondence with certain columns of the table. In this case the parameter values are stored as a Microsoft Excel table (Fig. 3).

The design table is defined using the Knowledge toolbar from the Shape module, by entering its name and most importantly entering the correct allocation of the parameters that compose the design table. The user can modify the values in the design table by editing and then saving the Microsoft Excel associated file. The CATIA environment automatically detects the changes and then updates the part according to the new values. In order to store the values of the parameters was used association data like in the case of the objects generated in virtual environments $[12,13]$.

\section{Software tool testing}

In order to test the software tool used in automated design for the products of custom footwear type, the user has to follow a series of steps from the moment the application is launched until the custom product is obtained like a solid model.

The real object for experimental product is shown in Fig. 4, and the steps that have to be followed are below presented.

The first step is to launch the CATIA software by Dassault Systems. The second is to open the"Parameterized_boot. CATPart" file generated using the algorithm developed by the authors [4]. The third step consists of data inputting in an window named "Introduce the characteristic parameters of the human foot and the boot", which is automatically displayed on screen (Fig. 5). The user has to enter both the data related to the foot for which product customization is desired and the parameters of the boot. 


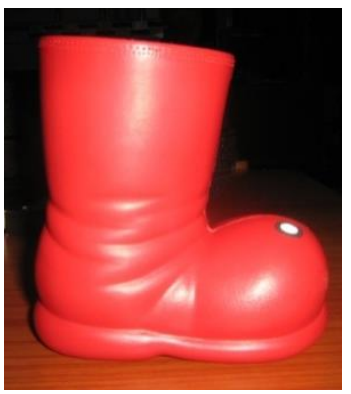

Fig. 4. Experimental footwear product.

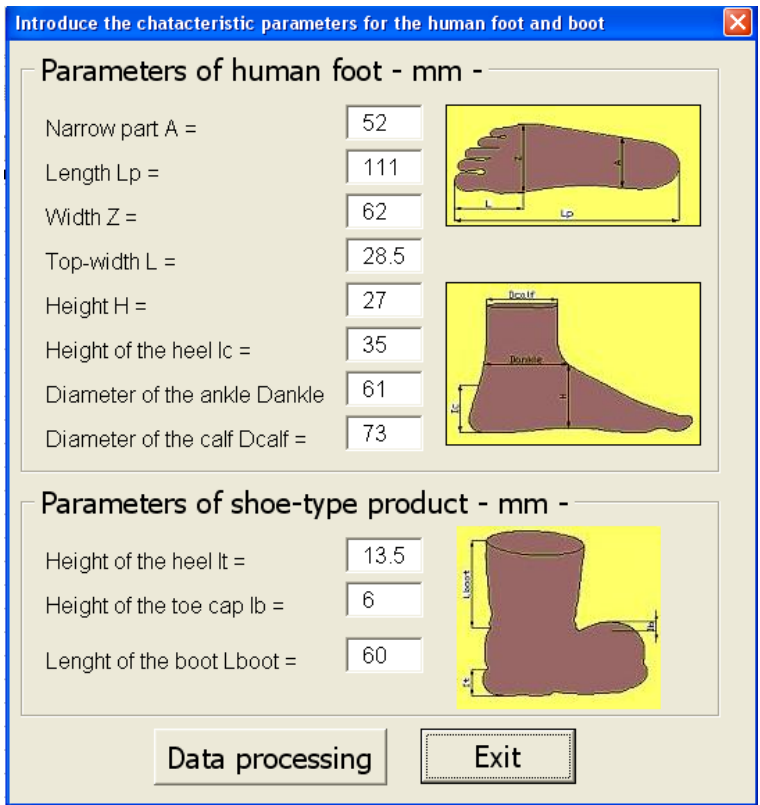

Fig. 5. Input parameters window.

\begin{tabular}{|c|c|c|c|c|c|c|c|c|c|c|c|c|}
\hline Microsoft & Excel - & Design_ & table1 & & & & & & & & - & \\
\hline 图] Eile É & yiew & Insert & Format & Iools & Data & Window Help & & & ype a qu & estion for $\mathrm{H}$ & 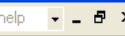 & \\
\hline $\mathrm{A}$ & $B$ & $c$ & D & $E$ & $F$ & G & $\mathrm{H}$ & & 1 & $J$ & K & \\
\hline 1 a $(\mathrm{mm}$ & Ip (mm) & $z(\mathrm{~mm})$ & I (mm) & $\mathrm{h}(\mathrm{mm})$ & ic (mm) & dankle $(\mathrm{mm})$ & dcalf $(\mathrm{mm})$ & & it $(\mathrm{mm})$ & ib $(\mathrm{mm})$ & lboot (mm) & \\
\hline $260^{\circ}$ & 130,0 & 70,0 & 30,0 & 30 & 40 & 7 & & 30 & 20,0 & 0,5 & & \\
\hline $14 \ldots, 1$ & Sheet1 & LSheet2 & KShee & & & & $|+| \mid$ & & & & & \\
\hline Ready & & & & & & & & & & NUM & & \\
\hline
\end{tabular}

Fig. 6. Design_table1 file.

The fourth step, press the "Data processing" button and the data are automatically written in the "Design_table1" Excel file (Fig. 6), and then press the "Exit" button to close the window. Finally, the designer can notice how the components of the considered object are automatically changed according to the data entered in step 3.

All parameters have default values, being at the basis of the initial product presented in the Fig. 4. For a better illustration of the whole customization process of a footwear type product, table 1 shows both the default values of the parameters and those subsequently modified. Fig. 7 shows two products of the boot type that were obtained with data sets from the table 1 . The final results are parametric CAD models obtained like a solid object. 
Table 1. Default and modified values of parameters.

\begin{tabular}{|l|c|c|c|}
\hline \multicolumn{1}{|c|}{ Parameter } & Symbol & $\begin{array}{c}\text { Default value } \\
{[\mathbf{~ m m ~ ] ~}}\end{array}$ & $\begin{array}{c}\text { Modified } \\
\text { value } \\
{[\mathbf{~ m m ~ ] ~}}\end{array}$ \\
\hline Specific length for narrowing of foot & A & 52 & 60 \\
\hline Length of foot & Lp & 110,6 & 130 \\
\hline Specific length for width of foot & Z & 61,4 & 70 \\
\hline $\begin{array}{l}\text { Length from top of foot up to section } \\
\text { where width of foot is known }\end{array}$ & L & 28,5 & 30 \\
\hline Height of boot heel & It & 13,5 & 20 \\
\hline Height of the foot & H & 27 & 30 \\
\hline The height of the boot toe cap & Ib & 6 & 0,5 \\
\hline The height of the human heel of the foot & Ic & 35 & 40 \\
\hline Specific diameter for human ankle & Dankle & 61 & 70 \\
\hline Height of boot & Lboot & 60 & 50 \\
\hline Specific diameter the human foot's calf & Dcalf & 73 & 80 \\
\hline
\end{tabular}

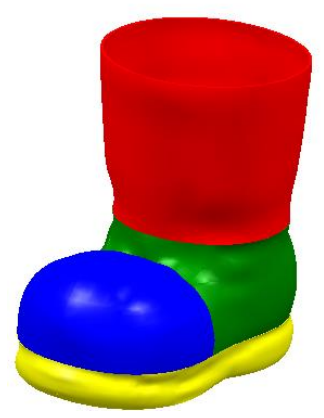

a)

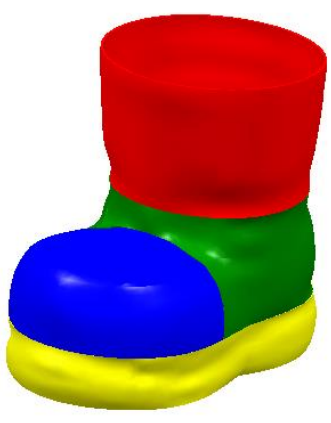

b)

Fig. 7. Final 3D CAD models based on automatically created solids: a) Default values of parameters; b) Modified values of parameters.

\section{Conclusion}

The paper presented a software tool developed by the authors for a footwear product type, using VBA and CATIA software system. In the tool is implemented an algorithm for the automated design of products with high level of customization for which, initially, no documentation was available. The paper also describes the steps for designing the products with a high level of customization, using the original software tool developed by the authors. The software tool is validated for a customized product which can be designed according to numeric data related to the human foot and product, entered by the user. Futures research will be focused on developing new case studies for different models of footwear products based on the methodology described by the authors. 
This work supported by the Sectoral Operational Programme Human Resources Development (SOP HRD), financed from the European Social Fund and by the Romanian Government under the project number POSDRU/89/1.5/S/59323 and we hereby acknowledge the structural founds project PRO-DD (POS-CCE, O.2.2.1., ID 123, SMIS 2637, ctr. No 11/2009) for providing the infrastructure used in this work.

\section{References}

1. W. Wang, Reverse Engineering: Technology of Reinvention (Taylor \& Francis Group, USA, 2010)

2. V. Raja and K. Fernandes, Reverse Engineering an Industrial Perspective (Springer Series in Advanced Manufacturing, UK, 2008)

3. G. Oancea, N.V. Ivan, R. Pescaru, AJME, 11 (4) (2013)

4. R. Pescaru, P. Kyratsis, G. Oancea, IOP Conf. Series: Materials Science and Engineering, 161 (2016)

5. R. Pescaru, G. Oancea, Advanced Materials Research, 7, 591-593, (2012)

6. $* * *$ http://www.geomagic.com/en/products-landing-pages/designx. Accessed 12 July 2017

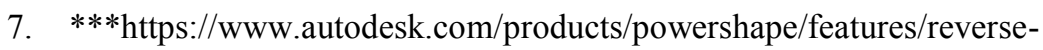
engineering/reverse-engineering. Accessed 12 July 2017

8. *** https://www.3ds.com/products-services/catia/. Accessed 12 July 2017

9. C. Utley, A Programmer's introduction to Visual Basic.NET, (Sams Publishing, Indianapolis, USA 2001)

10. J. Walkenbach, Excel VBA Programming for Dummies. 2nd Edition, (Wiley Publishing, Indianapolis, USA, 2010)

11. I. Ghionea, CATIA v5. Aplicaţii în inginerie mecanică (Ed. BREN, Bucharest, Romania 2009)

12. G. Oancea, F. Girbacia, A. Nedelcu, Software Module for Data Exchange Between AutoCAD and a Virtual Reality System, Product Engineering-Tools and Methods Based on Virtual Reality (Springer Netherlands, 2008)

13. S.A. Haba, G. Oancea, Journal of Advanced Manufacturing Technology, 80 (5), (2015) 